\title{
One-Electron Oxidation of Heterodinuclear Organometallic Compounds Having Polyphosphido Bridges ${ }^{\dagger}$
}

\author{
Rainer F. Winter*,‡ and William E. Geiger*,§ \\ Department of Chemistry, University of Vermont, Burlington, Vermont 05405
}

Received September 17, 2002

\begin{abstract}
The electrochemical behavior of several heterometallic compounds having polyphosphido bridges has been investigated. Reversible one-el ectron oxidations were observed for $\mathrm{Cp} * \mathrm{Fe}$ $\left(\mathrm{P}_{5}\right) \mathrm{TaCp}^{\prime \prime}(\mathbf{2}), \mathrm{Cp} * \mathrm{Fe}\left(\mathrm{P}_{5}\right)\left[\mathrm{Ir}_{2}(\mathrm{CO})_{2} \mathrm{Cp}_{2}\right]$ (3), and $\mathrm{Cp}^{\prime \prime \prime}{ }_{2} \mathrm{CO}_{2}\left(\mathrm{P}_{2}\right)_{2}$ (4) $\left(\mathrm{Cp}^{*}=\mathrm{C}_{5} \mathrm{M}_{5}, \mathrm{Cp}^{\prime \prime}=\right.$

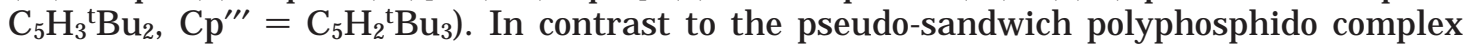
$\mathrm{Cp}^{*} \mathrm{FeP}_{5}(\mathbf{1})$, compounds $\mathbf{2}-\mathbf{4}$ undergo very facile oxidations and the corresponding monocations may be generated by bulk electrolysis or by reaction with ferrocenium ion. $E_{1 / 2}$ values ( vs $\mathrm{Cp}_{2} \mathrm{Fe}^{0 /+}$ ) for the oxidations are $-0.24 \mathrm{~V}$ for $\mathbf{2},-0.58 \mathrm{~V}$ for $\mathbf{3}$, and $-0.33 \mathrm{~V}$ for $\mathbf{4}$ in $\mathrm{CH}_{2} \mathrm{Cl}_{2} / 0.1 \mathrm{M}\left[\mathrm{NBu}_{4}\right]\left[\mathrm{PF}_{6}\right]$, in contrast to $0.57 \mathrm{~V}$ for $\mathbf{1}$. Although ESR spectra of $\mathbf{2}^{+}$display hyperfine coupling to ${ }^{181} \mathrm{Ta}$, the SOMO appears to have only minor Ta character. IR spectroelectrochemistry of the $3 / 3^{+}$couple reveals an increase of $v_{\mathrm{CO}}$ of only $11 \mathrm{~cm}^{-1}$, indicating that the oxidation of $\mathbf{3}$ also occurs predominantly at the iron center. The fact that the Fe-based oxidations of $\mathbf{2}$ and $\mathbf{3}$ are more negative than that of $\mathbf{1}$ by ca. 0.8 and 1.15 $V$, respectively, is ascribed to differences in the iron formal oxidation state which arise from the structural variations of the $\mathrm{P}_{5}$ bridging groups.
\end{abstract}

\section{Introduction}

Within the context of ongoing research in heterodinuclear polyorganometallic chemistry, ${ }^{1-8}$ compounds containing polyphosphido bridges have drawn some attention owing to the variety of structural and bridging modes possible with these ligands. ${ }^{9}$ Some el ectrochemical studies have been reported on sandwich compounds containing the cyclopentadienyl-like pentaphosphacycl opentadienyl $\left(\mathrm{P}_{5}\right)$ or hexaphosphabenzene $\left(\mathrm{P}_{6}\right)$ ligand, such as $\mathrm{Cp}^{*} \mathrm{FeP}_{5}{ }^{10}(\mathbf{1})$ and $\mathrm{Cp}_{2} \mathrm{M}_{2}\left(\mathrm{P}_{6}\right)(\mathrm{M}=\mathrm{Cr}, \mathrm{Mo}, \mathrm{W}$,

${ }^{\dagger}$ Dedicated to Prof. Otto J . Scherer of University of Kaiserslautern on his becoming emeritus.

¥ Present address: Institut für Anorganische Chemie, Universität Stuttgart, Pfaffenwaldring 55, D-70569 Stuttgart, Germany. E-mail: winter@iac.uni-stuttgart.de.

$\S$ E-mail: wgeiger@zoo.uvm.edu.

(1) Gates, B. C. Chem. Rev. 1995, 95, 511.

(2) Ichikawa, M. Adv. Catal. 1992, 38, 283.

(3) Aubart, M. A.; Bergman, R. G. J . Am. Chem. Soc. 1996, 118, 1793.

(4) Nashner, M. S.; Somerville, D. M.; Lane, P. D.; Alder, D. L.; Shapley, J . R.; Nuzzo, R. G. J . Am. Chem. Soc. 1996, 118, 12964.

(5) Mukerjee, S.; Srinivasan, S.; Soriaga, M. P.; McBreen, J J J . Electrochem. Soc. 1995, 142, 1409.

(6) (a) Lemoine, P. Coord. Chem. Rev. 1988, 83, 169. (b) Zanello, P. Coord. Chem. Rev. 1988, 83, 169. (c) Geiger, W. E.; Connelly, N. G. Adv. Organomet. Chem. 1985, $24,87$.

(7) Collins, B. Y.; Koide, Y.; Schauer, C. K.; White, P. S. Inorg. Chem. 1997, 36, 6172.

(8) (a) Barr, M. E.; Adams, B. R.; Weller, R. R.; Dahl, L. F. J . Am. Chem. Soc. 1991, 113, 3052. (b) Barr, M. E.; Dahl, L. F. Organome tallics 1991, 10, 3991.

(9) See, for example: (a) Scherer, O.J . Angew. Chem., Int. Ed. Engl . 1985, 24, 924. (b) Scheer, M. Z. Chem. 1990, 29, 41. (c) Barr, M. E.; Adams, B. R.; Weller, R. R.; Dahl, L. E. J . Am. Chem. Soc. 1991, 113, 3052. (d) Scherer, O. J . Angew. Chem., Int. Ed. Engl. 1990, 29, 1004. (e) Scherer, O. J . Acc. Chem. Res. 1999, 32, 751. (f) Ehses, M.; Romerosa, A.; Peruzzini, M. Top. Curr. Chem. 2002, 220, 107.

(10) Winter, R. F.; Geiger, W. E. Organometallics 1999, 18, 1827 and references therein.
V). ${ }^{11}$ Because the electronic structures of the latter are similar to that of a triple-decker complex, they show electrochemical behavior typical of a highly del ocalized multi-metallic system. ${ }^{11}$ Very little has appeared ${ }^{8,9 b}$ on the redox properties of multinuclear complexes having phosphido bridges which are not $\mathrm{Cp}$ analogues. We now report electrochemical results on two structurally characterized ${ }^{12}$ compounds having $\mathrm{Cp} *$ Fe linked to either a monometallic or dimetallic moiety through a more irregular $\mathrm{P}_{5}$ ligand. In $\mathrm{Cp} * \mathrm{Fe}\left(\mathrm{P}_{5}\right) \mathrm{TaCp}$ " (2), ${ }^{13}$ one of the $\mathrm{P}-\mathrm{P}$ bonds of the $\mathrm{P}_{5}$ group is broken and the 18-electron configuration is achieved for both metals by the formation of an $\mathrm{Fe}-\mathrm{Ta}$ bond. Although the $\mathrm{P}_{5}$ system remains cyclic in $\mathrm{Cp} * \mathrm{Fe}\left(\mathrm{P}_{5}\right)\left[\mathrm{Ir}_{2}(\mathrm{CO})_{2} \mathrm{Cp}_{2}{ }_{2}\right](3)$, it is no longer planar. In this case a metal-metal bond is not needed to achieve an 18-electron configuration for $\mathrm{Fe}^{12}$

As will be shown below, the one-electron oxidations of $\mathbf{2}$ and $\mathbf{3}$ are surprisingly facile, with $\mathrm{E}_{1 / 2}$ values that are 0.80 and $1.15 \mathrm{~V}$ more negative, respectively, than the value of $0.57 \mathrm{~V}$ vs $\mathrm{Cp}_{2} \mathrm{Fe}^{0 /+}$ measured for $\mathbf{1}^{0 /+} .10$ Spectroscopic measurements (ESR, IR) indicate that, despite the contrasting $E_{1 / 2}$ values, the oxidations are localized primarily on the Cp*Fe moiety. The dicobalt complex $\mathrm{Cp}^{\prime \prime}{ }_{2} \mathrm{CO}_{2}\left(\mathrm{P}_{2}\right)_{2}$ (4) was also investigated, although in less detail since some electrochemistry had been reported earlier on the closely related complex $\mathrm{Cp}_{2}{ }_{2} \mathrm{CO}_{2}\left(\mathrm{P}_{2}\right)_{2} \cdot{ }^{8 b}$

(11) Scherer, O. J .; Schwalb, J .; Swarowsky, H.; Kaim, W.; Gross, R. Chem. Ber. 1988, 121, 443.

(12) Compounds 2 and 3: Detzl, M.; Mohr, T.; Scherer, O. J .; Wolmershäuser, G. Angew. Chem., Int. Ed. Engl. 1994, 33, 1110. Compound 4: Scherer, O.J .; Berg, G.; Wolmershäuser, G. Chem. Ber. 1995, 128, 635 . $1,2,4$.

(13) $\mathrm{Cp} *=\eta^{5}-\mathrm{C}_{5} \mathrm{Me}_{5}, \mathrm{Cp}^{\prime \prime}=\eta^{5}-\mathrm{C}_{5} \mathrm{H}_{3}{ }^{\mathrm{t}} \mathrm{Bu}_{2}-1,3, \mathrm{Cp}^{\prime \prime \prime}=\eta^{5}-\mathrm{C}_{5} \mathrm{H}_{2}{ }^{\mathrm{t}} \mathrm{Bu}_{3-}$ 

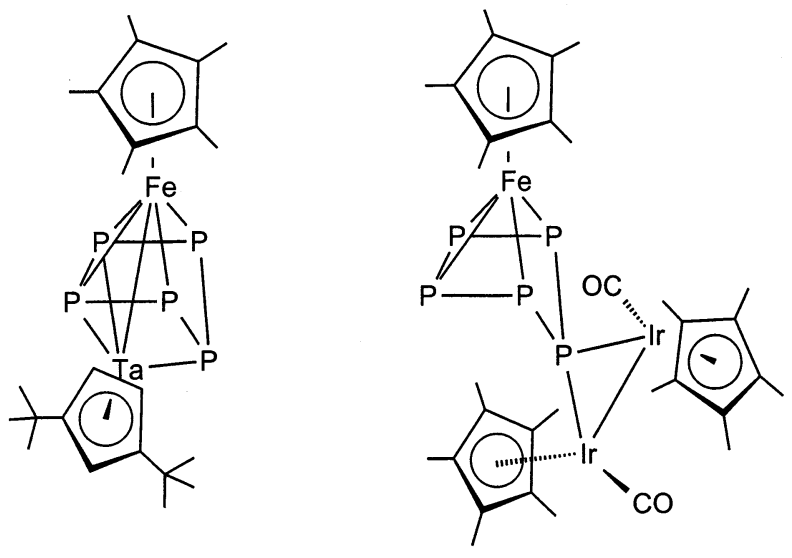

2

3
Table 1. Electrochemical Potentials (vs $\mathrm{Cp}_{2} \mathrm{Fe}^{\mathrm{0} /+}$ ) of Selected Polyphosphido Complexes in Nonaqueous Solvents Containing 0.1 M $\left[\mathrm{NBu}_{4}\right]\left[\mathrm{PF}_{6}\right]$

\begin{tabular}{|c|c|c|c|c|}
\hline \multirow[b]{2}{*}{ compd } & \multirow[b]{2}{*}{ solvent } & \multicolumn{2}{|c|}{ oxidn } & \multirow[b]{2}{*}{ redn } \\
\hline & & $0 / 1+$ & oxdn of 1+ & \\
\hline $\begin{array}{l}\left.\text { Cp*Fe(P } P_{5}\right) \mathrm{TaCp}^{\prime \prime}(\mathbf{2}) \\
\mathbf{2} \\
\mathrm{Cp} \mathrm{F}^{*} \mathrm{Fe}\left(\mathrm{P}_{5}\right)\left[\mathrm{Ir}_{2}(\mathrm{CO})_{2} \mathrm{Cp}_{2}{ }_{2}\right] \\
\quad(\mathbf{3})\end{array}$ & $\begin{array}{l}\mathrm{CH}_{2} \mathrm{Cl}_{2} \\
\mathrm{THF} \\
\mathrm{CH}_{2} \mathrm{Cl}_{2}\end{array}$ & $\begin{array}{l}-0.24 \\
-0.14 \\
-0.58\end{array}$ & $\begin{array}{l}\text { ca. } 1^{\text {a }} \\
\text { not measd } \\
0.25^{d}\end{array}$ & $\begin{array}{l}-2.58^{b} \\
-2.56^{c} \\
\text { not measd }\end{array}$ \\
\hline $\begin{array}{l}\mathrm{Cp}^{\prime \prime \prime}{ }_{2} \mathrm{Co}_{2}\left(\mathrm{P}_{2}\right)_{2}(\mathbf{4}) \\
\mathrm{Cp}_{2} \mathrm{Co}_{2}\left(\mathrm{P}_{2}\right)_{2}(\mathbf{5}) \\
\mathrm{Cp}^{*} \mathrm{FeP}_{5}(\mathbf{1})\end{array}$ & $\begin{array}{l}\mathrm{CH}_{2} \mathrm{Cl}_{2} \\
\mathrm{CH}_{3} \mathrm{CN} \\
\mathrm{CH}_{2} \mathrm{Cl}_{2}\end{array}$ & $\begin{array}{r}-0.33 \\
-0.16 \mathrm{e} \\
0.57 \mathrm{~g}\end{array}$ & $\begin{array}{l}0.33 \\
0.15^{\text {ef }}\end{array}$ & $-2.00^{f, g}$ \\
\hline
\end{tabular}

a Broad, ill-defined multielectron wave. ${ }^{b}$ I rreversible wave close to solvent background. ${ }^{c} E_{p c}$ at scan rate $=0.1 \mathrm{~V} / \mathrm{s}$; irreversible wave of two-electron height. ${ }^{d} E_{p a}$ at scan rate $=0.1 \mathrm{~V} / \mathrm{s}$; see text for more details. ${ }^{e}$ Reference $8 \mathrm{~b} .{ }^{\mathrm{f}}$ Chemically irreversible oneel ectron process. ${ }^{9}$ Reference 10.

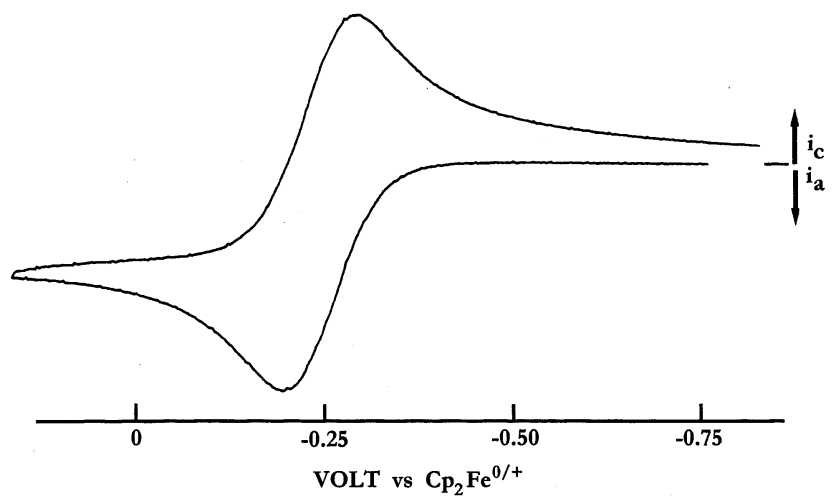

Figure 1. Cydic voltammogram of $0.5 \mathrm{mM} 2$ in $\mathrm{CH}_{2} \mathrm{Cl}_{2}$ / $0.1 \mathrm{M}\left[\mathrm{NBu}_{4}\right]\left[\mathrm{PF}_{6}\right]$ at a glassy-carbon electrode $(2 \mathrm{~mm}$ diameter) at ambient temperature and a scan rate of 0.1 V/s.

\section{Results}

In $\mathrm{CH}_{2} \mathrm{Cl}_{2} /\left[\mathrm{NBu}_{4}\right]\left[\mathrm{PF}_{6}\right]$, compounds $\mathbf{2}-\mathbf{4}$ each undergo an essentially reversible one-electron oxidation to the corresponding monocation, followed by a further oneelectron oxidation which varies in its chemical reversibility. In addition, irreversible reductions of compounds $\mathbf{2}$ and $\mathbf{3}$ were observed in THF; since the cathodic processes gave a number of el ectroactive products, they were not studied in detail.

Table 1 gives the measured $E_{1 / 2}$ and $E_{\text {peak }}$ potentials vs ferrocene/ferrocenium for these compounds and for the monometallic analogue $\mathbf{1}$.

The oxidation of $\mathbf{2}$ (Figure 1) was shown to be a chemically and electrochemically reversible, diffusioncontrolled, one-electron process $\left(\mathrm{E}_{1 / 2}=-0.24 \mathrm{~V}\right.$ in $\mathrm{CH}_{2}$ $\mathrm{Cl}_{2},-0.14 \mathrm{~V}$ in THF). The diffusion coefficients, $\mathrm{D}$, measured by chronoamperometry with $4 \mathrm{~s}$ step times, ${ }^{17}$ were $1.0 \times 10^{-5} \mathrm{~cm}^{2} / \mathrm{s}$ in THF/0.15 M [NBu 4 [PF 6 at $300 \mathrm{~K}$ and $5.6 \times 10^{-6} \mathrm{~cm}^{2} / \mathrm{s}$ at $271 \mathrm{~K}$. The chemical reversibility of the couple was confirmed by cyclic voltammetry (CV, scan rates of 0.05 to $0.5 \mathrm{~V} / \mathrm{s}$ ) and double-potential step chronoamperometry (1-4 s step times) at room temperature. The essentially Nernstian nature of $\mathbf{2} / \mathbf{2}^{+}$was indicated by the fact that the $\Delta \mathrm{E}_{\mathrm{p}}$ values in $\mathrm{CV}$ scans were very close to those observed for ferrocene under the same conditions (typically $70 \mathrm{mV}$ at $\mathrm{v}=0.05 \mathrm{~V} / \mathrm{s})$.

(17) Bard, A. J .; Faulkner, L. R. Electrochemical Methods, 2nd ed.; Wiley: New York, 2001; pp 207-210. 
Exhaustive bulk oxidation of $\mathbf{2}$ at $276 \mathrm{~K}$ in $\mathrm{CH}_{2} \mathrm{Cl}_{2} /$

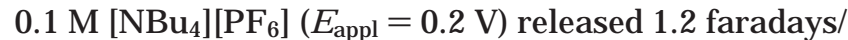
equiv as the solution went from an olive green to a dark red-brown. Comparison of rotating-Pt-el ectrode scans before and after electrolysis suggested the efficient production of the monocation $\mathbf{2}^{+}$. After a period of about $40 \mathrm{~min}$, a back-electrolysis was carried out at $\mathrm{E}_{\text {appl }}=$ $-0.6 \mathrm{~V}$, requiring 1.1 faradays/equiv and regenerating an essentially quantitative amount of neutral $\mathbf{2}$. When this "forward and backward" el ectrolysis was repeated, a small amount $(<5 \%)$ of a secondary product was formed which had an oxidation wave of modest chemical reversibility at $E_{1 / 2}=0.57 \mathrm{~V}$, identical with that of $\mathbf{1}$. The presence of $\mathbf{1}$ as a side product was confirmed by addition of a genuine sample of $\mathrm{Cp} \mathrm{FeP}_{5}$, which enhanced the current of the secondary product wave. The long-term oxidation process of $\mathbf{2}$ is as described in eq $\mathbf{1}$.

$$
\begin{gathered}
\mathrm{Cp} * \mathrm{Fe}\left(\mathrm{P}_{5}\right) \mathrm{TaCp} " \stackrel{-0.24 \mathrm{~V}}{\mathbf{2}} \\
{\left[\mathrm{e}^{-}\right.} \\
{\left[\mathrm{Cp} F \mathrm{Fe}\left(\mathrm{P}_{5}\right) \mathrm{TaCp}^{\prime \prime}\right]^{+} \stackrel{\text { slow }}{\longrightarrow}} \\
\mathbf{2}^{+} \mathrm{CpFe}_{5}+\text { unknown Ta product } \\
\mathbf{1}
\end{gathered}
$$

Attempts to isolate X-ray-quality crystals of $\mathbf{2}^{+}$were unsuccessful. Chemical oxidation of $\mathbf{2}$ by 1 equiv of $\left[\mathrm{Cp}_{2}-\right.$ $\mathrm{Fe}]\left[\mathrm{BF}_{4}\right]$ in $\mathrm{CH}_{2} \mathrm{Cl}_{2}$ produced only orange-brown microcrystals after 3 days at $240 \mathrm{~K}$. When this experiment was repeated in $\mathrm{CD}_{2} \mathrm{Cl}_{2}$, it was found by NMR spectroscopy that $\mathbf{2}^{+}$was undergoing slow decay to neutral $\mathbf{2}$ with some $\mathbf{1}$ also present. It was possible, however, to obtain ESR spectra of $\mathbf{2}^{+}$generated either by the bulk coulometric oxidations described above or by a chemical oxidation using $\left[\mathrm{Cp}_{2} \mathrm{Fe}\right]\left[\mathrm{BF}_{4}\right]$ in $1: 1 \mathrm{CH}_{2} \mathrm{Cl}_{2} / \mathrm{C}_{2} \mathrm{H}_{4} \mathrm{Cl}_{2}$. Fluid-solution spectra were recorded over the temperature range of 190-240 K, with increased resolution being obtained at higher temperatures. The spectra are consistent with the presence of an eight-line hyperfine splitting from the Ta nucleus: $\langle\mathrm{a}\rangle=42 \mathrm{G}$ and $\langle\mathrm{g}\rangle=$ 2.0940 (Figure 2a) $\left({ }^{181} \mathrm{Ta}, 99.99 \%, I=7 / 2\right)$. The frozensolution spectra were much more complex, with highly overlapped sets of apparent octets of hyperfine lines (Figure 2b). It appears that $\mathrm{A}_{T \mathrm{a}}$ is approximately 45$50 \mathrm{G}$ for two of the three principal directions, and in conjunction with the measured isotropic value of $42 \mathrm{G}$, a third $A_{T a}$ value of $25-35 \mathrm{G}$ is estimated. Using the measured and estimated hyperfine values and assuming approximate axial symmetry, one calculates less than $1 \%$ Ta 6 s character and 5-15\% Ta 3d character for the SOMO of $\mathbf{2}^{+} .18$ The dominant metal character in this radical appears to be at the ESR-silent Fe atom.

When the more strongly donating solvent THF was used in bulk anodic electrolyses of $\mathbf{2}$, several el ectroactive decomposition products were observed, the main

(18) Using a model of axial symmetry, one can estimate the fraction of $\mathrm{s}$ vs $\mathrm{p}$ and $\mathrm{d}$ character on the Ta nucleus. Since the maximum isotropic hyperfine splitting for ${ }^{181} \mathrm{Ta}$ is $5360 \mathrm{G}$, the measured value of $\langle a\rangle=42 \mathrm{G}$ gives $0.78 \%$ for the $6 \mathrm{~s}$ radical character. Using the estimated values of $A_{T a}(1)=A_{T a}(2)=45-50 \mathrm{G}$ and $A_{T a}(3)=25-35 \mathrm{G}$, along with a uniaxial theoretical hyperfine constant of $64 \mathrm{G}$ for ${ }^{181} \mathrm{Ta}$ one obtains a scatter of $5-15 \%$ tantalum $5 \mathrm{~d}$ character. For details of this treatment see: Weil, J. A.; Bolton, J. R.; Wertz, J. E. Electron Paramagnetic Resonance, Wiley: New York, 1994; Chapters 5 and 9 and Table G.4.
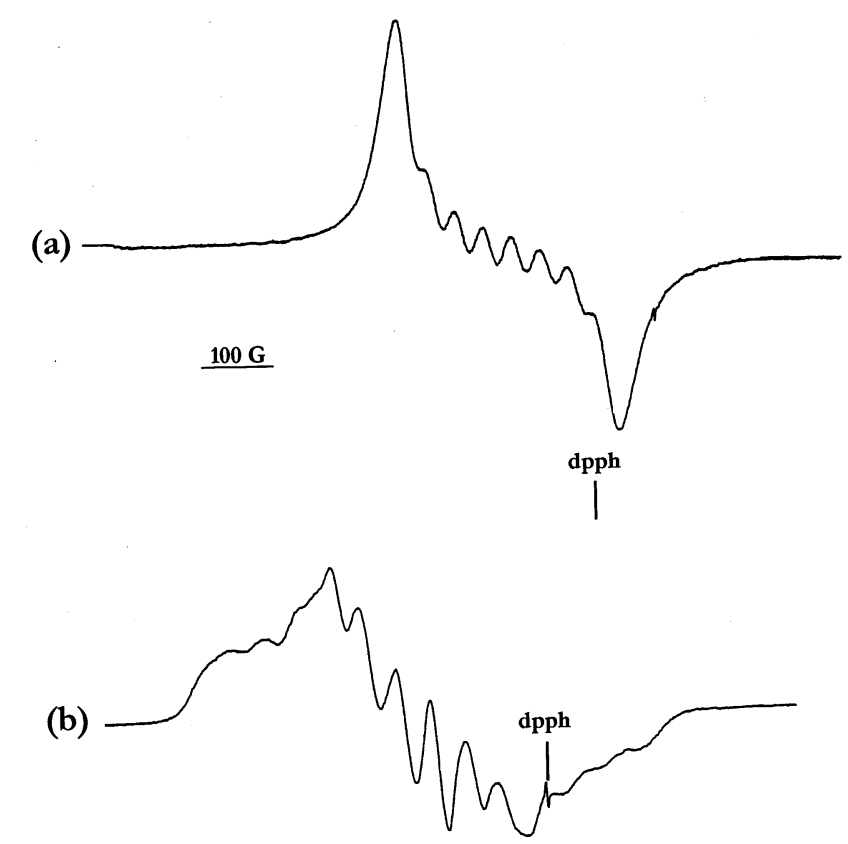

Figure 2. X-band ESR spectra of $\mathbf{2}^{+}$in $1: 1 \mathrm{CH}_{2} \mathrm{Cl}_{2} / \mathrm{C}_{2} \mathrm{H}_{4}-$ $\mathrm{Cl}_{2}$ : (a) fluid-solution spectrum at $240 \mathrm{~K}$; (b) frozen spectrum at $77 \mathrm{~K}$. The position of the dpph standard is indicated.

oxidation product being mononuclear $\mathbf{1}(\mathrm{T}=276 \mathrm{~K}$, dark green solution, 3 faradays/equiv).

The trinuclear Fel $r_{2}$ complex 3 undergoes two sequential one-electron oxidations at potentials of $E_{1 / 2}=$ $-0.58 \mathrm{~V}$ and $\mathrm{E}_{\mathrm{p}}=0.25 \mathrm{~V}$ in $\left.\mathrm{CH}_{2} \mathrm{Cl}_{2} / 0.1 \mathrm{M}^{2} \mathrm{NBu}_{4}\right]\left[\mathrm{PF}_{6}\right]$. The first of these, assigned to the couple $\mathbf{3} / \mathbf{3}^{+}$, is highly reversible, whereas the second, assigned to $3^{+} / \mathbf{3}^{2+}$, has the anodic shape of a slow electron-transfer process ${ }^{19}$ with a cathodic return feature suggestive of electrode product adsorption. The overall chemical reversibility of the $3 / 3^{+}$couple was investigated by bulk el ectrolysis of 3 at $265 \mathrm{~K}\left(\mathrm{E}_{\text {appl }}=-0.3 \mathrm{~V}, 1.1\right.$ faradays/equiv, dark green col or). Small waves arising from compound $\mathbf{1}$ were seen, indicating the slow decomposition of $\mathbf{3}^{+}$. Backelectrolysis ( $E_{\text {appl }}=-0.9 \mathrm{~V}, 0.56$ faradays/equiv) led to $50 \%$ regeneration of the starting material, 3 . F rom this experiment and from the time dependence of EPR intensities of solutions of $\mathbf{3}^{+}$, the half-life of the radical cation is esti mated as about $1 \mathrm{~h}$. The anodic el ectrolysis solution containing $\mathbf{3}^{+}$had a frozen-solution ESR spectrum of rhombic character with $g_{1}=2.2044, g_{2}=2.0483$, and $g_{3}=1.9981$. The average $g$ value of 2.0836 is consistent with the measured fluid solution spectrum, which has $\mathrm{g}=2.0820$, with a peak-to-peak width of 20 $\mathrm{G}$ at $250 \mathrm{~K}$. No hyperfine splittings were observed in either glassy or fluid solutions. I dentical ESR results were obtained by treating $\mathrm{CH}_{2} \mathrm{Cl}_{2} / \mathrm{C}_{2} \mathrm{H}_{4} \mathrm{Cl}_{2}$ solutions of 3 with $\left[\mathrm{Cp}_{2} \mathrm{Fe}\right]\left[\mathrm{BF}_{4}\right]$. The ESR spectra are reminiscent of those seen previously ${ }^{10}$ for $\mathbf{1}^{+}(2.1961,2.1095,2.0071$ (average 2.104)) and are consistent with a predominantly iron-based spin localization in $\mathbf{3}^{+}$.

(19) The anodic peak at $E_{p a}=0.25 V$ has a breadth of $E_{p a}-E_{p a / 2}$ of $105 \mathrm{mV}$ at $\mathrm{v}=0.1 \mathrm{~V} \mathrm{~s}^{-1}$, much larger than that (ca. $60 \mathrm{mV}$ ) expected for a reversible system under these conditions. The anodic peak current is only about $80 \%$ of that for the couple $3 / 3^{+}$, once again in keeping with the electrochemically irreversible nature of $3^{+} / 3^{2+}$. See ref $17, p p$ 234-243. 


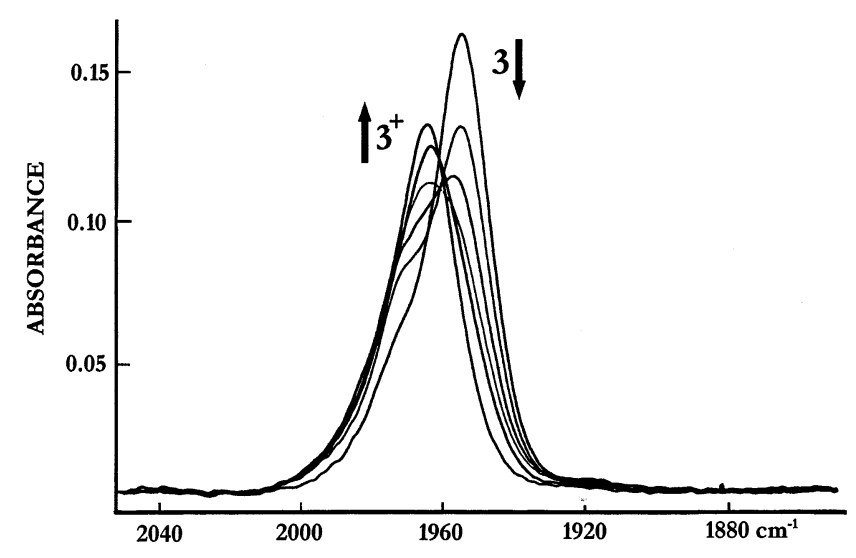

Figure 3. $v_{\mathrm{CO}}$ spectral changes upon IRTTLE oxidation of $2 \mathrm{mM} 3$ in $\mathrm{CH}_{2} \mathrm{Cl}_{2} / 0.1 \mathrm{M}$ [NBu$\left.u_{4}\right]\left[\mathrm{PF}_{6}\right]$. As the oxidation proceeds, the absorption of $\mathbf{3}\left(v_{\mathrm{CO}} 1953 \mathrm{~cm}^{-1}\right)$ is replaced by that of $\mathbf{3}^{+}\left(v_{\mathrm{CO}} 1964 \mathrm{~cm}^{-1}\right)$.
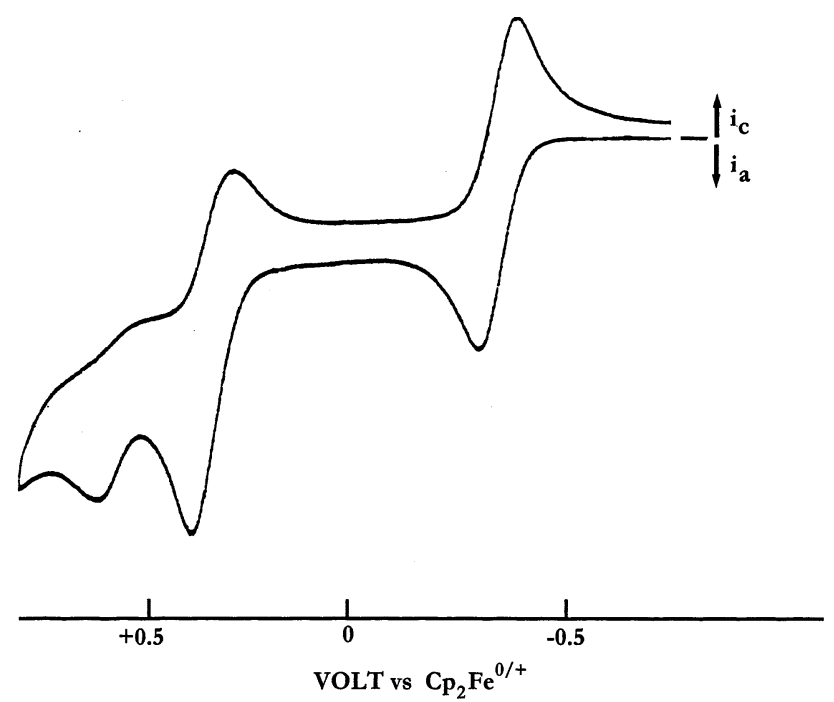

Figure 4. Cyclic voltammogram of $0.5 \mathrm{mM} 4$ in $\mathrm{CH}_{2} \mathrm{Cl}_{2} /$ $\left.0.1 \mathrm{M}^{2} \mathrm{NBu}_{4}\right]\left[\mathrm{PF}_{6}\right]$ at a glassy-carbon electrode $(2 \mathrm{~mm}$ diameter), at $T=250 \mathrm{~K}$ and a scan rate 0.1 of $\mathrm{V} / \mathrm{s}$. The small feature at $\mathrm{E}_{\mathrm{pa}}=0.65 \mathrm{~V}$ arises from the decomposition of $\mathbf{4}^{2+}$.

When a portion of the anodic electrolysis solution containing $\mathbf{3}^{+}$was removed for an IR analysis, a band at $v 1964 \mathrm{~cm}^{-1}$ was observed, shifted only $11 \mathrm{~cm}^{-1}$ from $v 1953 \mathrm{~cm}^{-1}$ for the neutral complex 3. Since a small band was also observed at $v 2037 \mathrm{~cm}^{-1}$, an IR-transparent thin-layer el ectrochemistry (IRTTLE) experiment ${ }^{15}$ was undertaken to clarify the assignments. In this case, electrolysis of $\mathbf{3}$ at $\mathrm{E}_{\mathrm{appl}}=0.1 \mathrm{~V}$ resulted in smooth conversion of $\mathbf{3}\left(v_{\mathrm{CO}} 1953 \mathrm{~cm}^{-1}\right)$ to $\mathbf{3}^{+}\left(v_{\mathrm{CO}} 1964 \mathrm{~cm}^{-1}\right)$ without production of IR-active side products (Figure 3). Back-reduction of $\mathbf{3}^{+}$regenerated over $80 \%$ of the original spectrum of $\mathbf{3}$. The very small increase in $v_{\mathrm{CO}}$ upon one-el ectron oxidation of $\mathbf{3}$ is strongly suggestive that the positive charge in $\mathbf{3}^{+}$lies predominantly with $\mathrm{Fe}$, rather than at the Ir atoms.

The dicobalt complex 4 displays two one-electronoxidation processes. The first of these, involving $\mathbf{4 / \mathbf { 4 } ^ { + }}$ $\left(E_{1 / 2}=-0.33 \mathrm{~V}\right)$ is essentially Nernstian, with a diffusion coefficient of $5.7 \times 10^{-6} \mathrm{~cm}^{2} / \mathrm{s}$ in $\mathrm{CH}_{2} \mathrm{Cl}_{2} / 0.1 \mathrm{M}$ $\left[\mathrm{NBu}_{4}\right]\left[\mathrm{PF}_{6}\right]$ at $296 \mathrm{~K}$. A second one-el ectron oxidation to $4^{2+}\left(E_{1 / 2}=0.33 \mathrm{~V}\right)$ has limited chemical reversibility at room temperature but is more reversible at $250 \mathrm{~K}$
(Figure 4). Electrochemical measurements for the very similar complex $\mathrm{Cp}_{2} \mathrm{CO}_{2}\left(\mathrm{P}_{2}\right)_{2}$ (5) concluded that it is reversibly oxidized to $\mathbf{5}^{+}$at $-0.16 \mathrm{~V}$, followed by an irreversible second oxidation at $0.15 \mathrm{~V}$. ${ }^{8 \mathrm{~b}}$ The present result for the $\mathbf{4} / \mathbf{4}^{+}$couple is consistent with the earlier finding for $\mathbf{5} / \mathbf{5}^{+}$, except for our measurement of a significantly larger separation between the first and second oxidations of $\mathbf{4}$ (ca. $660 \mathrm{mV}$ ) than the value of ca. $330 \mathrm{mV}$ estimated ${ }^{8 b}$ for $\mathbf{5}$.

Bulk oxidation of $\mathbf{4}$ in $\mathrm{CH}_{2} \mathrm{Cl}_{2}$ at $\mathrm{E}_{\text {appl }}=0 \mathrm{~V}$ resulted in the clean conversion to $\mathbf{4}^{+}(250 \mathrm{~K}, 1.03$ faradays/ equiv, change of color from brown of $\mathbf{4}$ to yellow-green of $\mathbf{4}^{+}$), and reverse electrolysis at $\mathrm{E}_{\mathrm{appl}}=-0.6 \mathrm{~V}$ gave back the starting material $\mathbf{4}$ in $95 \%$ yield. The oxidized solution gave a glassy ESR spectrum with a broad (200 $\mathrm{G}$ ) resonance having the appearance of an approximately axially symmetric $\mathbf{g}$ tensor with $g_{\|}$and $g_{\perp}$ close to 2.03. No hyperfine splittings were observed. When the generation of $\mathbf{4}^{+}$was repeated using $\left[\mathrm{Cp}_{2} \mathrm{Fe}\right]\left[\mathrm{BF}_{4}\right]$ as an oxidant, a fluid-solution spectrum was observed, but again the lines were too broad to allow assignment of hyperfine splittings.

\section{Discussion}

Two significant points about the one-electron oxidations of $\mathbf{2}$ and $\mathbf{3}$ are that (i) they occur at $E_{1 / 2}$ values that are strongly negative of $E_{1 / 2}$ for the oxidation of $\mathbf{1}$ and (ii) the spectral (ESR and IR) properties of $\mathbf{2}^{+}$and $\mathbf{3}^{+}$show that the oxidations of both $\mathbf{2}$ and $\mathbf{3}$ are essentially iron-based.

Strong evidence for this conclusion is the fact that $v_{\mathrm{CO}}$ increases by only $11 \mathrm{~cm}^{-1}$ in going from $\mathrm{Cp} * \mathrm{Fe}$ $\left(\mathrm{P}_{5}\right)\left[\mid \mathrm{Ir}_{2}(\mathrm{CO})_{2} \mathrm{Cp}{ }_{2}\right]$ to $\left[\mathrm{Cp} * \mathrm{Fe}\left(\mathrm{P}_{5}\right)\left\{\mathrm{Ir}_{2}(\mathrm{CO})_{2} \mathrm{Cp}{ }_{2}\right\}\right]^{+}$, whereas a much larger increase would be expected if the HOMO of $\mathbf{3}$ is primarily localized on the diiridium site. According to previous literature ${ }^{20}$ the oxidation of trinuclear metal-carbonyl clusters having del ocalization over all three metals results in $v_{\mathrm{CO}}$ increases of $60-80 \mathrm{~cm}^{-1}$. The simplest interpretation of the IR spectrum of $\mathbf{3}^{+}$is that the effect of oxidation at the iron center is transmitted through the $\sigma$ framework to the $I r_{2}$ center as an inductive effect.

A similar conclusion, namely that the spin distribution is minimally on the non-iron metal, is reached in evaluating the ESR spectra of $\mathbf{2}^{+}$. The hyperfine splitting from ${ }^{181} \mathrm{Ta}$ is prominent because this nucleus has a rather large nuclear $\mathrm{g}$ factor. ${ }^{21}$ The lack of a fully resolved glassy spectrum of $\mathbf{2}^{+}$(Figure 2 ), along with the possible role of quadrupole effects such as those found in other third-row-metal radicals, ${ }^{22}$ precludes an analysis of the Ta hyperfine splittings sufficient to give a detailed orbital assignment.

However, using reasonable approximations, ${ }^{18}$ we conclude that there is a spin density on Ta of ca. $10 \%$. Although there is not a broad literature of ESR spectra of heterodinuclear radicals having $\mathrm{M}-\mathrm{M}^{\prime}$ bonds, there has been a spectrum reported for the Ta-Co radical, $\mathrm{Cp}_{2} \mathrm{Ta}\left(\mu-\mathrm{CH}_{2}\right)_{2} \mathrm{CoCp}^{23}$ In that case, despite the demon-

(20) Robben, M. P.; Rieger, P. H.; Geiger, W. E. J . Am. Chem. Soc. 1999, 121, 367.

(21) See: Weil, J. A. et al. In ref 18, p 536.

(22) Connelly, N. G.; Emslie, D. J . H.; Klangsinsirikul, P.; Rieger, P. H.J . Phys. Chem. A 2002, 106, 51. 4853. 
strated presence of a $\mathrm{Ta}$-Co bond, the glassy spectrum showed a hyperfine interaction with only one of the metals. Since both metals have $\mathrm{I}=7 / 2$, an indirect assignment of the splitting was required, with the authors favoring an assignment to Ta rational ized on a preferred $\mathrm{Co}(\mathrm{III}) / \mathrm{Ta}$ (IV) electronic structure. A similar line of reasoning would suggest an assignment of $\mathrm{Fe}$ (II) $/ \mathrm{Ta}$ (IV) in $\mathbf{2}^{+}$(vide infra). Although this is surely an oversimplification of the electronic structure of the FeTa cation, it accentuates the point that a Ta-based oxidation of $\mathbf{2}$ is not necessary to account for the ESR properties of $\mathbf{2}^{+}$.

Finally, the ease of oxidation of $\mathbf{2}$ and $\mathbf{3}$ deserves comment, since the negative shifts compared to $\mathbf{1}$ (800 and $1150 \mathrm{mV}$, respectively) seem too large to be accounted for by simple inductive effects. Rather, the ease of oxidation is ascribed to changes in the formal oxidation state of the iron atom concomitant with changes in the bonding mode of the $\mathrm{P}_{5}$ ligand upon addition of one or two more transition metals for $\mathbf{2}$ and 3, respectively. For $\mathbf{1}$ itself, the bonding closely resembles that of ferrocene with an $\mathrm{Fe}(\mathrm{II})$ coordinated to $\mathrm{Cp}^{*-}$ and $\mathrm{P}_{5}{ }^{-}$ rings. In contrast, the $P_{5}$ unit in $\mathbf{2}$ is best described as an open chain pentaphosphapenta-1,4-dienetriide $\left(\mathrm{P}_{5}{ }^{3-}\right)$, following a formalism that assigns every two-coordinated phosphorus atom either a negative or a positive charge. ${ }^{24}$ The iron atom is coordinated to two $\mathrm{P}=\mathrm{P}$ bonds and to the pentamethylcyclopentadienide, while the

(24) von Schnering, H. G.; Hönle, W. Chem. Rev. 1988, 88, 243. tantalum atom forms bonds to another substituted cyclopentadienide and the three negatively charged terminal and central phosphorus atoms of the $\mathrm{P}_{5}$ chain. The resulting formal oxidation states of iron and tantalum are $+\mathrm{I}$ and $+\mathrm{IV}$, respectively.

In complex $\mathbf{3}$ the Fe atom is in essentially the same bonding environment as in $\mathbf{2}$, with the exception of the absence of an $\mathrm{Fe}-$ metal bond. The diamagnetism of this compound and the 18-electron rule suggest at least a partial contribution from a zwitterionic electronic structure involving a negatively charged $\mathrm{Fe}(0)$ atom counterbalanced by a positive charge on the central $\mathrm{P}$ atom of the cyclo- $\mathrm{P}_{5}$ ring. In this way a $\mathrm{PR}_{2}{ }^{+}$unit contributes two val ence electrons to the diiridium entity. The moiety $\left[\{\mathrm{Cp} *(\mathrm{CO}) \mid \mathrm{r}\}_{2}\left(u-\mathrm{PR}_{2}\right)\right]^{+}$thus achieves a 34-electron count, in agreement with the observed iridium-iridium bond. The $E_{1 / 2}$ values of the oxidations of compounds $\mathbf{1}-\mathbf{3}$ are therefore seen to parallel a decrease in the formal $\mathrm{Fe}$ oxidation state and are consistent with ESR and IR spectroscopic results which place the SOMO primarily on the Fe center in the cations of all three compounds.

Acknowledgment. We are grateful to the donors of the Petroleum Research Fund, administered by the American Chemical Society, to the National Science Foundation (Grant No. CHE97-05763), and to the DFG for support of this work. We are grateful for the interest of Prof. Scherer in this work and to his research group for providing samples of compounds 2-4. 